\title{
Development of Paediatric Non-Stage Prognosticator Guidelines for Population-Based Cancer Registries and Updates to the 2014 Toronto Paediatric Cancer Stage Guidelines
}

Sumit Gupta, $\mathrm{PhD}^{1 *}$, Joanne Aitken, $\mathrm{PhD}^{* 2}$, Ute Bartels, $\mathrm{MD}^{1}$, Nickhill Bhakta, $\mathrm{MD}^{3}$, Mihaela Bucurenci, $\mathrm{MD}^{4}$, James Brierley, $\mathrm{MB}^{5}$, Beatriz De Camargo, $\mathrm{PhD}^{6}$, Eric Chokunonga ${ }^{7}$, Jessica Clymer, $\mathrm{MD}^{8}$, Dana Coza, $\mathrm{MD}^{4}$, Chris Fraser, MD ${ }^{9}$, Soad Fuentes-Alabi, MD ${ }^{10}$, Gemma Gatta, $\mathrm{PhD}^{11}$, Thomas Gross, $\mathrm{MD}^{12}$, Zsuzsanna Jakab, $\mathrm{PhD}^{13}$, Betsy Kohler, $\mathrm{PhD}^{14}$, Tezer Kutluk, $\mathrm{MD}^{15}$, Florencia Moreno, $\mathrm{PhD}^{16}$, Kayo Nakata, $\mathrm{MD}^{17}$, Sari Nur, $\mathrm{MD}^{18}$, D. Maxwell Parkin, $\mathrm{MD}^{19,26}$, Lynne Penberthy, $\mathrm{PhD}^{20}$, Jason Pole, $\mathrm{PhD}^{21}$, Jenny N. Poynter, $\mathrm{PhD}^{22}, \mathrm{PhD}$, Kathy Pritchard-Jones, $\mathrm{MB}^{23}$, Oscar Ramirez, $\mathrm{MD}^{24}$, Lorna Renner, $\mathrm{MD}^{25}$, Eva Steliarova-Foucher, $\mathrm{PhD}^{26}$, Michael Sullivan, $\mathrm{MD}^{27}$, Rajaraman Swaminathan, $\mathrm{PhD}^{28}$, Liesbet Van Eycken, $\mathrm{MD}^{29}$, Tushar Vora, $\mathrm{MD}^{30}$, A. Lindsay Frazier, $\mathrm{MD}^{8}$

${ }^{1}$ Division of Haematology/Oncology, The Hospital for Sick Children, 555 University Avenue, Toronto, ON, Canada, M5G 1X8

${ }^{2}$ Cancer Council Queensland, 533 Gregory Terrace, Fortitude Valley, QLD 4066, Australia.

${ }^{3}$ Global Pediatric Medicine, St. Jude Children's Research Hospital, 262 Danny Thomas Place, Memphis, TN, 38105, USA

${ }^{4}$ Romanian National Child Cancer Registry, 154 Tomis Boulevard, PO Box 900591, Constanta

${ }^{5}$ Radiation Medicine Program, Princess Margaret Hospital, 610 University Avenue, Toronto, ON, Canada, M5G 2M9

${ }^{6}$ Research Center, National Cancer Institute National Cancer Institute, R. Andre Cavalcanti 37 Centro, Rio de Janeiro - RJ, 20231-050, Brazil

${ }^{7}$ The Zimbabwe National Cancer Registry, Parirenyatwa Hospital

Mazowe Street, 00000, Harare, Zimbabwe

${ }^{8}$ Dana-Farber/Boston Children's Cancer and Blood Disorders Center, 450 Brookline Avenue, Boston, MA 02215

${ }^{9}$ Department of Oncology, Children's Health Queensland Hospital, 501 Stanley Street, South Brisbane, Queensland 4101, Australia

${ }^{10}$ Ayúdame a Vivir Medical Center, Bulevar De Los Heroes, San Salvador, El Salvador

${ }^{11}$ Istituto Nazionale dei Tumori, Via Giacomo Venezian, 1, 20133 Milano MI, Italy

${ }^{12}$ National Cancer Institute, National Institute of Health, 9000 Rockville Pike, Bethesda, MD 20892, United States

${ }^{13}$ Hungarian Childhood Cancer Registry / Semmelweis University, Budapest, 1094, Budapest Tuzolto str. 7-9, Hungary

${ }^{14}$ North American Association of Central Cancer Registries, 2050 W. Iles, Suite A, Springfield, IL 62704-4194

${ }^{15}$ Department of Pediatric Oncology, Hacettepe University Faculty of Medicine and Cancer Institute, Ankara, Turkey

${ }^{16}$ Argentina National Cancer Institute, Av. Pres. Julio A. Roca 781, C1067ABC, Buenos Aires, Argentina

${ }^{17}$ Cancer Control Center, Osaka International Cancer Institute, 3 Chome-1-69 Otemae, Chuo Ward, Osaka, 541-8567, Japan

${ }^{18}$ Universitas Padjadjaran/ Dr. Hasan Sadikin General Hospital, Jl. Raya Bandung Sumedang KM.21, Hegarmanah, Kec. Jatinangor, Kabupaten Sumedang, Jawa Barat 45363, Indonesia 
${ }^{19}$ Nuffield Department of Population Health, University of Oxford, Oxford OX1 2JD, United Kingdom

${ }^{20}$ National Cancer Institute, National Health Institute, 9609 Medical Center Drive, Bethesda, MD 20892

${ }^{21}$ Pediatric Group of Ontario, 1014 - 480 University Avenue, Toronto, ON, M5G 1V2

${ }^{22}$ Department of Pediatrics, University of Minnesota, Minneapolis, MN, 55455

${ }^{23}$ University College London, 30 Guilford St, Holborn, London WC1N 1EH, United Kingdom

${ }^{24}$ Centro Médico Imbanaco, Cra. 38a \#\#\#5A-100, Cali, Valle del Cauca, Colombia

${ }^{25}$ University of Ghana School of Medicine, Slater Avenue, Accra, Ghana

${ }^{26}$ Section of Cancer Surveillance, International Agency for Research on Cancer, 150 Cours Albert Thomas, 69372 Lyon CEDEX 08, France

${ }^{27}$ Faculty of Medicine, University of Melbourne, Parkville VIC 3010, Australia

${ }^{28}$ Cancer Institute (WIA), East Canal Bank Rd, Gandhi Nagar, Adyar, Chennai, Tamil Nadu 600020, India

${ }^{29}$ Belgian Cancer Registry, Rue Royale 215, 1210 Saint-Josse-ten-Noode, Belgium

${ }^{30}$ Tata Memorial Centre, Dr. E, Dr Ernest Borges Rd, Parel, Mumbai, Maharashtra 400012, India

*Co-first authors

Corresponding Author: Dr. Sumit Gupta, Division of Haematology/Oncology, The Hospital for Sick Children, 555 University Avenue, Toronto, ON, Canada, M5G 1X8. +1 416-813-7654 x201681.sumit.gupta@sickkids.ca

Full Professors: Profs J Aitken, U Bartels, JD Brierley, B De Caramago, G Gatta, T Kutluk, K Pritchard-Jones, M Sullivan, R Swaminathan, AL Frazier 


\section{SUMMARY}

Population-based cancer registries (PBCRs) generate measures of cancer incidence and survival that are essential for cancer surveillance, research, and cancer control strategies. In 2014, the Toronto Paediatric Cancer Stage Guidelines were developed to standardize how PBCRs collect data on stage at diagnosis for childhood cancer cases. These Guidelines have been implemented in multiple jurisdictions to facilitate international comparative studies of incidence and outcome. Robust stratification by risk also requires data on key non-stage prognosticators (NSPs). Key experts and stakeholders utilized a modified-Delphi approach to establish principles guiding paediatric cancer NSP collection. Using these principles, recommendations were made on which NSPs should be collected for the major childhood malignancies. The 2014 Toronto Stage Guidelines were also reviewed and updated where necessary. Wide adoption of the resultant Paediatric NSP Guidelines and updated Stage Guidelines will enhance the harmonisation and utility of childhood cancer data provided by PBCRs. 


\section{Introduction and Rationale}

Population-based cancer registries (PBCRs) provide a complete picture of cancer incidence and survival within their jurisdictions and are the foundation for population-based cancer research and national cancer control strategies. ${ }^{1-5}$ Given their heterogeneity and rarity, childhood cancers represent a particular data management challenge for registries. ${ }^{6}$ With few known modifiable causes or prevention strategies at the current time, there is little scope at present for reducing childhood cancer incidence. Current cancer control efforts are mostly focused on improving survival by improving access to and the quality of treatment, or in some cases by facilitating earlier diagnosis. Outcome also depends on measurable prognostic factors that together determine the patient's "risk" of a poor outcome. Accurate risk stratification greatly facilitates interpretation and comparison of mortality and survival between jurisdictions or between time periods.

One of the most important prognostic factors for many childhood malignancies is stage, i.e., the anatomic extent of disease at diagnosis. To set international guidelines for the collection of childhood cancer stage by PBCRs, an expert group of cancer registrars, epidemiologists, and paediatric oncologists recommended in 2014 the staging system to be used by cancer registries for each of 18 childhood malignancies which together comprise the bulk of the childhood cancer burden. The resultant "Toronto Paediatric Cancer Stage Guidelines" (hereafter referred to as the Toronto Staging Guidelines) have been endorsed by major clinical and cancer registry organizations, and have been either piloted or fully implemented in several jurisdictions. ${ }^{7,8}$ For many childhood cancers, ${ }^{9,10}$ non stage prognostic factors (NSPs) are also important in risk 
stratification and commonly used in clinical settings. NSPs include a broad range of variables, including site, histology, cytogenetics, and serum markers.

A new group of experts convened at the International Agency for Research on Cancer (IARC) in 2019 to identify the key principles that should guide the collection of childhood cancer NSPs by PBCRs. Based upon these principles, the group also aimed to recommend which NSPs should be collected by cancer registries for the purposes of analysis and interpretation of population level cancer data, while respecting different capacities and resource levels of the registries. Finally, the group determined whether any updates to the 2014 Toronto Staging Guidelines were necessary. Our recommendations are not intended to reflect or guide clinical practice.

\section{Methods}

A panel of international experts and stakeholders, representing diverse fields of expertise (e.g. clinicians and epidemiologists), world regions, and country resource settings was assembled in order to ensure the most generalizable and feasible recommendations. ${ }^{11}$ Representatives from numerous cancer registries and registry associations were also invited. Invitees could nominate additional participants.

We undertook a modified-Delphi approach to consensus building, ${ }^{11,12}$ with the objective of identifying guiding principles relevant to the collection of paediatric cancer NSPs in PBCRs. An initial Delphi round was conducted by online survey. A search of Ovid Medline revealed only studies pertaining to specific childhood cancer cohorts. No studies provided general principles for selecting one NSP over another. The consensus workshop leaders (SG, LF, JA) therefore generated a list of candidate principles informed by conversations with key stakeholders. 
In round one, panelists were asked to rate each principle on a 5-point Likert scale $(1=$ strongly agree, $2=$ agree, $3=$ neither agree nor disagree, $4=$ disagree, $5=$ strongly disagree). ${ }^{11}$ Panelists were also asked to provide comments on each principle, and to suggest additional principles for inclusion. In accordance with published guidelines, consensus was defined as $\geq 75 \%$ of respondents either agreeing or strongly agreeing with a principle, (median score $\leq 2) .{ }^{11}$ Any principle with which $\geq 75 \%$ respondents disagreed or strongly disagreed was eliminated. In addition to rating the above principles, for each of the selected childhood cancers included in the original Toronto Staging Guidelines, participants were asked 1) whether any updates should be considered to the original stage guidelines and, 2) to suggest candidate NSPs for consideration.

A one-day in-person meeting was then held for all participants at the IARC in Lyon, France (October 19 th 2019). The group reviewed each approved principle for content and phrasing. Those principles not achieving consensus were further discussed in detail and were either revised and accepted, or rejected. Additional principles could be suggested and included if endorsed by the group. Finally, the entire set of principles achieving consensus was re-reviewed in order to minimize redundancy.

Panelists then broke into three working groups: hematologic malignancies, solid tumours, and neuro-oncology. Each group comprised epidemiologists, cancer registrars and paediatric oncologists with appropriate malignancy expertise. Groups were first tasked with deciding whether any updates to the original Toronto Staging Guidelines should be endorsed. For each cancer, groups then selected which NSPs should be endorsed, guided by the principles that had 
achieved consensus. Working groups were provided with the results of the online questionnaire, but were also free to suggest alternatives. Each working group then presented their recommendations to the full group, and after incorporating suggestions and refinements, a final recommendation was made.

\section{Participants and Response Rates}

Through an iterative process, workshop leaders and an additional author (ESF) identified 38 potential participants, $33(86 \cdot 8 \%)$ of whom accepted the invitation to participate (Table 1). These 33 participants represented 21 countries across six continents; $12(36 \cdot 2 \%)$ represented low- and middle-income countries (LMICs). Participants had expertise in paediatric oncology ( $\mathrm{n}=19$; $57 \cdot 6 \%)$, epidemiology $(n=9 ; 27 \cdot 3 \%)$, and cancer registration $(n=25 ; 75 \cdot 8 \%)$, with several individuals having multiple areas of expertise. Key stakeholder groups were represented, including the TNM Working Group of the Union for International Cancer Control (UICC), International Agency for Research on Cancer (IARC), United States National Cancer Institute (NCI), Surveillance, Epidemiology, and End Results (SEER) Program, the International Association of Cancer Registries (IACR), the North American Association of Central Cancer Registries (NAACCR), The European Network of Cancer Registries (ENCR), EUROCARE, and the African Cancer Registry Network (AFCRN). Of the 33 participants who accepted the invitation, $32(97 \cdot 0 \%)$ participated in the online survey and $29(87 \cdot 9 \%)$ were present for the face-to-face meeting in Lyon, France.

\section{Principles for Collection of Paediatric Non-Stage Prognosticators}


In the initial online Delphi round, 10 principles were proposed. In addition, four criteria with which NSPs could be prioritized for collection were also proposed. The original principles are listed in Supplemental Table 1. Eight of these principles achieved consensus (bolded statements in Supplemental Table). During the face-to-face discussion, one of the remaining principles that did not achieve consensus was retained (statement 9) and the other eliminated (statement 6). Three additional principles were adopted, and two principles achieving consensus were eliminated to avoid redundancy. Several principles were modified to improve phrasing without altering content. Of the four criteria by which NSPs could be prioritized for collection, three achieved consensus while one was eliminated. During the face-to-face meeting, an additional criterion was added. The final endorsed list of 11 core principles is shown in Table 2 and discussed in detail below.

Participants overwhelmingly endorsed the importance of collecting NSPs for cases of paediatric cancer in PBCRs (Principle 1). A primary reason for doing so was to allow stratified comparison of outcomes between groups or over time (Principle 2). Participants emphasized however that NSPs should not be prioritized over the collection of anatomic stage data as defined by the Toronto Staging Guidelines. ${ }^{7}$

Discussion also focused on the purpose of cancer registries. The core purpose of registries is the capture of all incident cases in a population and often also their follow-up for vital status to provide measures of incidence, and population-based survival, to support population cancer surveillance, policy and planning. ${ }^{13}$ Some, but not all PBCRs embrace additional purposes, such as producing mortality and prevalence estimates, providing a sample frame for population 
research, conducting linkage studies using other databases to evaluate treatment and health system performance measures, clinical trial participation, real-world verification of clinical trial findings and aetiological research. ${ }^{14}$ The stakeholders, purpose, and available resources of each PBCR will dictate many aspects of its structure, priorities, and activities including whether and which NSPs are collected. Where sufficient resources are available, collecting NSPs will enhance the ability to conduct aetiological and epidemiological studies (Principle 3) and to enable the assessment of concordance of treatment patterns with guidelines when linking to treatment data (Principle 4).

Participants agreed that not all NSPs should be collected by registries (Principle 5) given the burden of data collection associated with each additional variable. Candidate NSPs should be measurable by methods that are standardized and reproducible (Principle 6). ${ }^{15}$ Testing for the NSP should ideally be widely available within the relevant jurisdiction and health system (Principle 7). Several participants noted the tension between real-world availability of a specific NSP and the aspiration to increase availability, particularly in low- and middle-income country (LMIC) settings. Caution is warranted when NSP data may be non-randomly missing given the risk of bias in such situations. Candidate NSPs should be considered essential to clinical practice for either decision-making or prognostication (Principle 8). Where multiple NSPs are highly correlated, registries should collect only one of the correlated variables (Principle 9). For cancers with a large number of NSPs that meet the above principles, a limited set should be prioritized for collection (Principle 10). 
Such prioritization should be based on several criteria (Principle 11), including the prognostic impact of the NSP, feasibility of collection, availability, and the goals of the specific registry. Significant discussion occurred regarding whether the prevalence of the NSP among the target patient group should be considered when prioritizing NSPs for collection. Several participants noted that an NSP with low prevalence might still be highly prognostic, or that an NSP might not be prevalent overall but be highly prevalent in a particular subpopulation. For these reasons, prevalence was removed from the list of prioritization criteria to consider.

\section{Endorsing Non-Stage Prognosticators for Specific Malignancies}

Working groups adopted the UICC framework for data collection prioritization, which consists of three categories: Essential vs. Additional vs. New and Promising. ${ }^{16}$ "Essential” variables should be collected by all registries that have started to collect NSPs, while "Additional" NSPs should be considered by registries with increased resources and/or data access. "New and Promising" NSPs are not endorsed currently for collection but are nonetheless highlighted as potential candidates for future endorsements.

Some of the most important NSPs (e.g. histology, cytogenetics) are already on the list of the essential minimum data items to be collected by PBCR, although some registries may have difficulties to obtain complete and valid information. It is important to note that histologic and in some cases cytogenetic subgroups have specific ICD-O codes but have been shown to be unreliably coded or collected. ${ }^{17,18}$ The adoption and correct use of the ICD-O-3 classification ${ }^{19}$ and its updates

(http://www.iacr.com.fr/index.php?option=com_content\&view=category\&layout=blog\&id=100 
\&Itemid $=577$ ) is recommended. These guidelines for collection of NSPs identify the morphologic entities that have important prognostic value for paediatric cancers. Participants recognized the increasing complexity and expansion of tumour classifications defined by molecular and genetic subtypes.

Several categories of NSPs were not considered by the group. Response to therapy, either radiologic or pathologic, was excluded given wide variation at a population-level in the treatment received, time point and modality of assessment, and definition of response. An exception was made for Wilms tumour (WT) where both staging and histology after initial treatment is core to risk stratification. ${ }^{20}$ Host factors such as underlying syndromes (e.g. Down Syndrome in acute leukemia $^{21}$ or cancer predisposition conditions (e.g. Li-Fraumeni Syndrome) ${ }^{22}$ were also not considered, though may be in the future. Finally, very rare childhood cancers were generally not considered. However some very rare cancers may be particularly prevalent in certain jurisdictions, such as adrenocortical carcinomas in Southern Brazil. ${ }^{23}$ In these contexts, registries may choose to collect locally endorsed NSPs for these cancers.

Recommendations for collecting NSPs for the selected childhood cancers are shown in Table 3 and discussed below.

\section{Haematologic Malignancies}

For acute lymphoblastic leukemia (ALL), age and initial white blood cell (WBC) count at diagnosis and lineage (precursor-B or precursor-T lymphoblastic leukaemia coded according to ICD-O-3) were endorsed as the "essential" NSPs for risk stratification. ${ }^{24}$ As most registries 
collect dates of both birth and diagnosis, age at diagnosis can be calculated for patients. Cytogenetics was endorsed as an "additional" NSP, again, coded according to ICD-O-3. Though minimal residual disease (MRD) is a crucial prognosticator, as a marker of response to therapy it was not considered as discussed above in the paragraph on response to therapy. ${ }^{25}$ For acute myeloid leukemia (AML), no NSPs were regarded as "essential." Cytogenetics was endorsed as an "additional" NSP with the most relevant for collection including the core binding factor leukemias [t(8;21)(q22;q22) and inv(16)(p13·1q22)], t(15;17)(q22;q11-12), and 11q23 abnormalities. ${ }^{26}$ Where possible, registries should also consider collecting Monosomy 7 , Monosomy 5, and the presence of FLT3-ITD mutations. ${ }^{26}$

No NSPs were endorsed for either chronic myeloid leukemia or Hodgkin lymphoma. For nonHodgkin lymphoma (NHL), histologic subtype is an "essential" NSP, with the most common paediatric subtypes being Burkitt lymphoma, lymphoblastic lymphomas, diffuse large B-cell lymphoma, and anaplastic large cell lymphoma.

\section{$\underline{\text { Solid Tumours }}$}

For neuroblastoma, N-myc status was endorsed as an "additional" NSP. ${ }^{27}$ For WT, histologic classification was endorsed as an "essential" NSP. However, participants noted several challenges in collecting this variable. First, treatment protocols for WT differ, with some embracing upfront surgical resection and others using neoadjuvant chemotherapy. ${ }^{20}$ Histologic subtype at the time of resection consequently differs between these two approaches as certain favorable histologic subtypes present at diagnosis may be obviated by chemotherapy. Second, WT histologic subtypes are currently not included in ICD-O-3. Participants strongly endorsed 
inclusion of WT histology in future iterations and the use of " $y$ " prefixes, as in the Toronto Paediatric Cancer Stage Guidelines and classically in the TNM classification, to distinguish between the histology following the initial surgical vs. neoadjuvant approaches. Several prognostic genetic lesions in WT (1p, 16q, 1q) were not endorsed but considered "new and promising" NSPs. ${ }^{20}$ For rhabdomyosarcoma, histologic subtype and anatomic location, both recorded using ICD-O-3, were endorsed as "essential" ${ }^{28}$ Cytogenetics, specifically the presence of FKR-PAX3 or FKR-PAX7 was endorsed as an "additional" NSP. ${ }^{28}$ No NSPs were endorsed for non-rhabdomyosarcoma soft tissue sarcoma, osteosarcoma, Ewing sarcoma, hepatoblastoma, retinoblastoma, testicular cancer or ovarian cancer.

\section{Central Nervous System Tumours}

For astrocytomas, histologic subtype (often based on grade) and anatomic location, again both recorded according to ICD-O-3, were endorsed as "essential" NSPs. ${ }^{29}$ The presence of H3K27M mutations was endorsed as an "additional" NSP for collection by registries. ${ }^{30}$ Participants highlighted BRAF status (BRAF V600E mutation, KIAA1549:BRAF fusion) as a "new and promising" NSP that may warrant collection in the future. ${ }^{31}$ For medulloblastoma, molecular classification was endorsed as an "additional" NSP, categorized as WNT vs. SHH vs. Group 3/Group 4 medulloblastomas, also collected by ICD-O-3.32 No NSPs were endorsed for ependymomas. For all central nervous system (CNS) tumours, as a marker of response to therapy, extent of resection was not endorsed.

\section{Updates to the Toronto Staging Guidelines}


The following updates to the Toronto Staging Guidelines were endorsed. For ALL, the inclusion of testicular involvement was again considered and rejected for its rarity and uncertain prognostic significance when appropriate treatment is given. Participants noted that cytospin is required when determining CNS involvement. For AML, the earlier endorsement of a staging system was removed as CNS positivity does not have significant prognostic impact in either clinical trials or population-based studies to date. ${ }^{33,34}$ For NHL, the newly proposed IPNHLSS was considered but not adopted as currently it is rarely used in clinical practice or clinical trials, and because its finely-divided categories were considered of limited relevance at a populationlevel. ${ }^{35}$

Participants noted that all renal tumours with the exception of renal cell carcinomas should use the currently endorsed staging systems for WT; renal cell carcinomas should be staged according to the TNM classification. As the staging systems endorsed for osteosarcoma and Ewing sarcoma are identical, it was suggested to combine these into a single recommendation for all bone tumours. For hepatoblastoma, PRETEXT staging was previously a "Tier 3" recommendation but was moved to "Tier 2 " status. ${ }^{36}$ For retinoblastoma, the $8^{\text {th }}$ edition AJCC staging system was considered but not adopted as it was deemed unnecessarily detailed for purposes of PBCRs. ${ }^{37}$ Adding Group A-E intraocular classifications to "Tier 2" recommendations was also rejected given subjectivity and operator dependence. For germ cell tumours, both testicular and ovarian, participants noted that the S category, referencing serum tumour marker elevation, was an integral part of TNM staging in "Tier 2" recommendations. For astrocytomas, staging as local vs. metastatic was endorsed, though participants acknowledged that the latter would be rare. 
The updated Toronto Staging Guidelines are illustrated in Table 4, designated the 2019 Toronto Paediatric Cancer Stage Guidelines. The Toronto Staging Guidelines Manual is available on the UICC website and will be updated to reflect these changes and include the Paediatric NSP Guidelines.

\section{Implementation}

Both the Toronto Staging Guidelines and the Paediatric NSP Guidelines explicitly pertain to PBCRs and not to clinical practice. Several participants noted however the importance of recognition by clinicians of the utility and value of PBCRs, and the crucial value of clinical collaboration in improving data completeness and quality. Experts from both high-income countries and LMICs gave examples of how bidirectional communication between clinicians and cancer registrars had led to both high quality childhood cancer data and new research endeavours. Participants also highlighted the need for development of standardized training resources for both the Toronto Staging and and NSP Guidelines to facilitate uniform implementation and thus comparability between registries.

It is again worth noting that of all the "essential" NSPs endorsed by participants (Table 3), all but presenting WBC count at diagnosis in ALL are already represented through various ICD-O-3 topography, behavior, and histology codes. This highlights that the quality of data capture is critical; integrated pathology data capture will help ensure precise diagnoses are captured and that the use of "not otherwise specified" is minimized. Checks of data validity in the registries are also recommended. Providing feedback to originating pathology departments may improve the overall data validity. Finally, several participants highlighted that natural language 
processing of medical records, record linkages to other data sources, and retrospective data collection holds potential to facilitate the collection of both stage and NSP data efficiently and at lower cost. ${ }^{38,39}$

\section{Conclusions}

We recommend that PBCRs should collect both stage and NSPs for childhood cancers commensurate with their resources and jurisdictional priorities. In addition to adopting the updated 2019 Toronto Paediatric Cancer Stage Guidelines, registries should strongly consider collecting the NSPs identified in the proposed NSP Guidelines. Using both the 2019 Toronto Staging and NSP Guidelines will further improve the quality and utility of childhood cancer data in PBCRs and will increase the informative value and interpretation of the international variation in childhood cancer incidence and outcomes.

\section{Declaration of Interests}

The authors declared no relevant conflicts of interest. Where authors are identified as personnel of IARC / World Health Organization (WHO), the authors alone are responsible for the views expressed in this article and they do not necessarily represent the decisions, policy or views of IARC/ WHO.

\section{Author Contributions}

SG, ALF and JFA conceived of the study idea and design, with additional input from ESF. SG conducted the analysis and wrote the first draft of the manuscript. All authors were involved in the data interpretation and crucial revisions of the report, and approved the final version 


\section{Acknowledgments}

The consensus meeting was funded by the Garron Family Cancer Centre at the Hospital For Sick Children. The funding source had no influence on the proceedings of the meeting, the decision to publish, or the writing of the manuscript. We acknowledge the support of Cancer Australia through a national initiative to improve population cancer data on stage, treatment and recurrence. KPJ is funded in part by the National Institute for Health Research (NIHR) Great Ormond Street Hospital Biomedical Research Centre, We wish to acknowledge the efforts and help of Ms. Meghan Cook and Ms. Veda Zabih (Sickkids) in coordinating the consensus process, and Ms Anastasia Dolya and Ms Katiuska Veselinovic (IARC) for their help with the meeting organisation.

\section{$\underline{\text { Search Strategy and Selection Criteria }}$}

In order to generate candidate principles that would guide the collection of childhood cancer stage by population-based cancer registries, Ovid Medline was searched using the following terms: “exp Neoplasms/” AND “exp Registries/” AND “exp Prognosis/” AND “exp Child/”. The search was limited to articles in English and published from 2000 updated to the end of 2018. The 905 identified articles pertained to specific cohorts with particular malignancies and not candidate principles. 


\section{REFERENCES}

1. Smith BD, Smith GL, Hurria A, Hortobagyl GN, Buchholz TA. Future of cancer incidence in the United States: Burdens upon an aging, changing nation. J Clin Oncol 2009; 27: 2758-65.

2. Hershman DL, Wright JD. Comparative effectiveness research in oncology methodology: Observationa data. J Clin Oncol 2012; 30(24): 4215-22.

3. Bray F, Znaor A, Cueva P, et al. Planning and developing population-based cancer registration in low-and middle-income settings. Lyon, France: International Agency for Research on Cancer, 2014.

4. Steliarova-Foucher E, Colombet M, Ries LAG, et al. International incidence of childhood cancer, 2001-10: a population-based registry study. Lancet Oncol 2017; 18(6): 719-31.

5. Bray F, Ferlay J, Soerjomataram I, Siegel RL, Torre LA, Jemal A. Global Cancer Statistics 2018: GLOBOCAN Estimates of Incidence and Mortality Worldwide for 36 Cancers in 185 Countries. CA Cancer J Clin 2018; In press.

6. Ward E, DeSantis C, Robbins A, Kohler B, Jemal A. Childhood and adolescent cancer statistics, 2014. CA Cancer J Clin 2014; 64: 83-103.

7. Gupta S, Aitken JF, Bartels U, et al. Paediatric cancer stage in population-based cancer registries: the Toronto consensus principles and guidelines. Lancet Oncol 2016; 17(4): e163-72.

8. Aitken JF, Youlden DR, Moore AS, et al. Assessing the feasibility and validity of the Toronto Childhood Cancer Stage Guidelines: a population-based registry study. Lancet Child Adolesc Health 2018; 2(3): 173-9.

9. Webber C, Gospodarowicz M, Sobin LH, et al. Improving the TNM classification: Findings from a 10-year continuous literature review. Int J Cancer 2014; 135: 371-8.

10. Chawla N, Yabroff KR, Mariotto AB, McNeel TS, Schrag D, Warren JL. Limited validity of diagnosis codes in Medicare claims for identifying cancer metastases and inferring stage. Ann Epidemiol 2014; 24: 666-72.

11. Loblaw DA, Prestrud AA, Somerfield MR, et al. American Society of Clinical Oncology Clinical Practice Guidelines: Formal Systematic Review-Based Consensus Methodology. J Clin Oncol 2012; 30: 3136-40.

12. Jones J, Hunter D. Consensus methods for medical and health services research. BMJ 1995; 311: 376-80.

13. Parkin DM. The evolution of the population-based cancer registry. Nat Rev Cancer 2006; 6(8): 603-12.

14. Tucker TC, Durbin EB, McDowell JK, Huang B. Unlocking the potential of populationbased cancer registries. Cancer 2019; 125(21): 3729-37.

15. Poste G, Compton CC, Barker AD. The national biomarker development alliance: confronting the poor productivity of biomarker research and development. Exp Rev Mol Diagn 2015; 15: 211-8.

16. Brierley J, Gospodarowicz M, Wittekind C. The TNM Classification of Malignant Tumours. 8th ed. Oxford; 2017.

17. Gupta S, Pole JD. The validity of pediatric cancer diagnoses in a population-based general cancer registry in Ontario, Canada. BMC Cancer 2016; 16(1): 885. 
18. Clarke CA, Undurraga DM, Harasty PJ, Glaser SL, Morton LM, Holly EA. Changes in cancer registry coding for lymphoma subtypes: Reliability over time and relevance for surveillance and study. Cancer Epidemiol Biomarkers Prev 2006; 15: 630-8.

19. Fritz A, Percy C, Jack A, et al., editors. International Classification of Diseases for Oncology, Third Edition, First Revision. Geneva: World Health Organization; 2013.

20. Dome JS, Graf N, Geller JI, et al. Advances in Wilms tumor treatment and biology: Progress through international collaboration. J Clin Oncol 2015; 33: 2999-3007.

21. Hasle $\mathrm{H}$, Clemmensen IH, Mikkelsen M. Risks of leukaemia and solid tumours in individuals with Down's syndrome. Lancet 2000; 355(9199): 165-9.

22. Malkin D, Nichols KE, Zelley K, Schiffman JD. Predisposition to pediatric and hematologic cancers: a moving target. Am Soc Clin Oncol Educ Book 2014: e44-55.

23. Balmant NV, de Souza Reis R, de Oliveira Santos M, de Carmargo B, Gatta G. Rare cancers in childhood and adolescence in Brazil: First report of data from 19 population-based cancer registries. Cancer 2019; 125(15): 2638-46.

24. Hunger SP, Mullighan CG. Acute lymphoblastic leukemia in children. New Engl J Med 2015; 373: 1541-2.

25. Borowitz MJ, Devidas M, Hunger SP, et al. Clinical significance of minimal residual disease in childhood acute lymphoblastic leukemia and its relationship to other prognostic factors: a Children's Oncology Group study. Blood 2008; 111(12): 5477-85.

26. Creutzig $U$, van den Heuvel-Eibrink MM, Gibson $B$, et al. Diagnosis and management of acute myeloid leukemia in children and adolescents: recommendations from an international expert panel. Blood 2012; 120: 3187-205.

27. Tolbert VP, Mattay KK. Neuroblastoma: Clinical and biological approach to risk stratification and treatment. Cell Tissue Res 2018; 372(2): 195-209.

28. Skapek SX, Ferrari A, Gupta AA, et al. Rhabdomyosarcoma. Nat Rev Dis Primers 2019; 5(1).

29. International Classification of Disease for Oncology (ICD-O) - 3rd edition, 1st revision. 3rd, 1st revision ed. Geneva: World Health Organization; 2013.

30. Khuong-Quang DA, Buczkowicz P, Rakopoulos P, et al. K27M mutation in histone H3.3 defines clinically and biologically distinct subgroups of pediatric diffuse intrinsic pontine gliomas. Acta Neuropathol 2012; 124: 439-47.

31. Bergthold G, Bandopadhayay P, Bi WL, et al. Pediatric low-grade gliomas: How modern biology reshapes the clinical field. Biochem Biophys Acta 2014; 1845(2): 294-307.

32. Taylor MD, Northcott PA, Korshunov A, et al. Molecular subgroups of medulloblastoma: The current consensus. Acta Neuropathol 2012; 123: 465-72.

33. Johnston DL, Alonzo TA, Gerbing RB, Lange BJ, Woods WG. The presence of central nervous system disease at diagnosis in pediatric acute myeloid leukemia does not affect survival: A Children's Oncology Group study. Pediatr Blood Cancer 2010; 55(3): 414-20.

34. Youlden DR, Gupta S, Frazier AL, et al. Stage at diagnosis for children with blood cancers in Australia: application of the Toronto Childhood Cancer Stage Guidelines in a populationbased national childhood cancer registry. Pediatr Blood Cancer 2019; 66(6): e27683.

35. Rosolen A, Perkins SL, Pinkerton C, et al. Revised International Pediatric Non-Hodgkin Lymphoma Staging System. J Clin Oncol 2015; 33(18): 2112-8. 
36. Roebuck DJ, Aronson D, Clapuyt P, et al. 2005 PRETEXT: a revised staging system for primary malignant liver tumours of childhood developed by the SIOPEL group. Pediatr Radiol 2007; 37(2): 123-32.

37. Amin MB, Greene FL, Edge SB, et al. The Eighth Edition AJCC Cancer Staging Manual: Continuing to build a bridge from a population-based to a more "personalized" approach to cancer staging. CA Cancer J Clin 2017; 67(2): 93-9.

38. Liao KP, Cai T, Savova Gk, et al. Development of phenotype algorithms using electronic medical records and incorporating natural language processing. BMJ 2015; 350: h1885.

39. Osborne JD, Wyatt M, Westfall AO, Willig J, Bethard S, Gordon G. Efficient identification of nationally mandated reportable cancer cases using natural language processing and machine learning. J Am Med Inform Assoc 2016; 23(6): 1077-84.

40. World Health Organisation. WHO Definition of region groupings. 2014. www.who.int/healthinfo/global_burden disease/definition_regions/en (accessed November 7th 2014).

41. Pui $\mathrm{CH}$. Central nervous system disease in acute lymphoblastic leukemia: prophylaxis and treatment. Hematology Am Soc Hematol Educ Program 2006; (142-6).

42. Metzger ML, Dome JS. Current therapy for Wilms' tumor. The Oncologist 2005; 10: 81526.

43. Chantada G, Doz F, Antonelli CB, et al. A proposal for an international retinoblastoma staging system. Pediatr Blood Cancer 2006; 47: 801-5. 
Table 1: Characteristics of participants $(\mathrm{N}=33)$

\begin{tabular}{|l|c|}
\hline & N (\%) \\
\hline Gender & \\
\hline Male & $13(40)$ \\
\hline Female & $20(61)$ \\
\hline Geographic area & \\
\hline Canada/USA & $11(33)$ \\
\hline Europe & $8(24)$ \\
\hline Asia & $5(15)$ \\
\hline Latin America & $4(12)$ \\
\hline Africa & $2(6)$ \\
\hline Oceania & $3(9)$ \\
\hline Resource setting* & \\
\hline HIC & $21(64)$ \\
\hline LMIC & $12(36)$ \\
\hline Area of expertise** & \\
\hline Clinical paediatric oncology & $19(58)$ \\
\hline Epidemiology & $9(27)$ \\
\hline Cancer registration & $25(76)$ \\
\hline
\end{tabular}

HIC - high-income country; LMIC - low- or middle-income country; USA - United States of America

*Based on World Bank definitions of $\mathrm{HIC}$ and $\mathrm{LMIC}^{40}$

**Figures do not add to $100 \%$ as individuals could have more than one area of expertise 
Table 2. Guiding principles of the collection of non-stage prognosticators of childhood malignancies in population-based registries

\begin{tabular}{|c|}
\hline Rationale for Collection \\
\hline 1. Cancer registries should collect data on NSPs for cases of pediatric cancer when appropriate \\
\hline $\begin{array}{l}\text { 2. A primary reason for collecting NSPs in registries, in addition to Toronto Stage, is to allow stratified } \\
\text { comparison of outcomes between groups or over time. }\end{array}$ \\
\hline $\begin{array}{l}\text { 3. An additional reason for collecting NSPs in registries is to enhance the ability to conduct etiological and } \\
\text { epidemiological studies }\end{array}$ \\
\hline $\begin{array}{l}\text { 4. An additional reason for collecting NSPs in registries with the ability to link to treatment data is to assess } \\
\text { concordance with treatment guidelines }\end{array}$ \\
\hline Collection of Non-Stage Prognosticators \\
\hline 5. Not all NSPs should be collected by registries \\
\hline 6. The methods to measure the NSP must be standardized and reproducible \\
\hline 7. Within the relevant jurisdiction and health system, testing for the NSP should ideally be widely available \\
\hline $\begin{array}{l}\text { 8. NSPs collected by registries should be considered essential to clinical practice for either decision making } \\
\text { or prognostication. }\end{array}$ \\
\hline $\begin{array}{l}\text { 9. For cancers where multiple NSPs are highly correlated, registries should only collect one of the } \\
\text { correlated NSPs }\end{array}$ \\
\hline 10. For cancers with a large number of NSPs, a limited set should be prioritized for collect by registries \\
\hline $\begin{array}{l}\text { 11. Prioritization of which NSPs to collect should be based on the following: a) Prognostic impact; b) } \\
\text { Feasibility; c) Availability, and; d) Registry purpose }\end{array}$ \\
\hline
\end{tabular}

NSP - non-stage prognosticator 
Table 3. The Lyon Paediatric Cancer Non-Stage Prognosticator Guidelines

\begin{tabular}{|c|c|c|c|c|}
\hline Malignancy & Essential & Additional & New and Promising & Comments \\
\hline \multicolumn{5}{|c|}{ HAEMATOLOGIC MALIGNANCIES } \\
\hline ALL & $\begin{array}{l}\text { Age } \\
\text { Initial WBC } \\
\text { Lineage }\end{array}$ & Cytogenetics & - & $\begin{array}{l}\text { 1. Lineage can be divided into precursor B-cell vs. precursor T-cell (using ICD- } \\
\text { O-3* categories) } \\
\text { 2. Cytogenetic categories using ICD-O-3 classification } \\
\text { 3. MRD not considered (response to therapy) }\end{array}$ \\
\hline AML & - & Cytogenetics & - & $\begin{array}{l}\text { 1. Cytogenetic categories using ICD-O-3 classification; most relevant discussed } \\
\text { in text. } \\
\text { 2. MRD not considered (response to therapy) }\end{array}$ \\
\hline CML & - & - & - & \\
\hline $\mathrm{HL}$ & - & - & - & \\
\hline NHL & Histology & - & - & 1. Most common subtypes in childhood (see text) have unique ICD-O-3 codes \\
\hline \multicolumn{5}{|l|}{ SOLID TUMOURS } \\
\hline Neuroblastoma & - & $\mathrm{N}-\mathrm{myc}$ & - & \\
\hline Wilms tumour & Histology & - & $1 \mathrm{p}, 16 \mathrm{q}, 1 \mathrm{q}$ & $\begin{array}{l}\text { 1. Histologic sub-classification will depend on if assessed before or after } \\
\text { adjuvant chemotherapy; see text for details }\end{array}$ \\
\hline Rhabdomyosarcoma & $\begin{array}{c}\text { Histology } \\
\text { Anatomic location }\end{array}$ & Cytogenetics & - & $\begin{array}{l}\text { 1. Histologic categories based on ICD-O-3 classification } \\
\text { 2. Anatomic location captured through ICD-O-3 topography codes }\end{array}$ \\
\hline $\begin{array}{l}\text { Non- } \\
\text { rhabdomyosarcoma } \\
\text { soft tissue sarcomas }\end{array}$ & 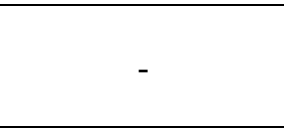 & - & - & \\
\hline Osteosarcoma & - & - & - & \\
\hline Ewing sarcoma & - & - & - & \\
\hline Retinoblastoma & - & - & - & \\
\hline Hepatoblastoma & - & - & - & \\
\hline Testicular & - & - & - & \\
\hline Ovarian & - & - & - & \\
\hline \multicolumn{5}{|c|}{ CENTRAL NERVOUS SYSTEM TUMOURS } \\
\hline Astrocytoma & $\begin{array}{l}\text { Histology/Grade } \\
\text { Anatomic location }\end{array}$ & H3K27M mutation & BRAF status & 1. Histologic categories/grade based on ICD-O-3 classification \\
\hline Medulloblastoma & - & $\begin{array}{l}\text { Molecular } \\
\text { classification }\end{array}$ & - & 1. Molecular classification using ICD-O-3 classification \\
\hline Ependymoma & - & - & - & \\
\hline
\end{tabular}


Table 4. Updated 2019 Toronto Paediatric Cancer Stage Guidelines

\begin{tabular}{|c|c|c|}
\hline Malignancy & Tier 1 Staging System & Tier 2 Staging System \\
\hline \multicolumn{3}{|c|}{ HAEMATOLOGIC MALIGNANCIES } \\
\hline \multirow{3}{*}{ ALL } & CNS negative & $\mathrm{CNS}^{4140}$ \\
\hline & \multirow{2}{*}{ CNS positive } & CNS 2 \\
\hline & & CNS 3 \\
\hline AML & None & None \\
\hline CML & None & None \\
\hline $\mathrm{HL}$ & & \\
\hline \multirow{4}{*}{ NHL } & \multirow{3}{*}{ Limited } & St. Jude/Murphy - Stage I \\
\hline & & St. Jude/Murphy - Stage II \\
\hline & & St. Jude/Murphy - Stage III \\
\hline & Advanced & St. Jude/Murphy - Stage IV \\
\hline \multicolumn{3}{|l|}{ SOLID TUMOURS } \\
\hline \multirow{4}{*}{ Neuroblastoma } & Localized & INRGSS - Localized L1 \\
\hline & Locoregional & INRGSS - Locoregional L2 \\
\hline & Metastatic & INRGSS - Metastatic M \\
\hline & INRGSS - MS Disease & INRGSS - MS Disease \\
\hline \multirow{4}{*}{$\begin{array}{l}\text { Renal tumours (except } \\
\text { RCCs) }\end{array}$} & \multirow{3}{*}{ Localized } & Stage I/ y-Stage I ${ }^{4241,40}$ \\
\hline & & Stage II / y-Stage II \\
\hline & & Stage III / y-Stage III \\
\hline & Metastatic & Stage IV \\
\hline \multirow{4}{*}{ Rhabdomyosarcoma } & \multirow{3}{*}{ Localized } & TNM Stage I \\
\hline & & TNM Stage II \\
\hline & & TNM Stage III \\
\hline & Metastatic & TNM Stage IV \\
\hline \multirow{4}{*}{$\begin{array}{l}\text { Non-rhabdomyosarcoma } \\
\text { soft tissue sarcomas }\end{array}$} & \multirow{3}{*}{ Localized } & TNM Stage I \\
\hline & & TNM Stage II \\
\hline & & TNM Stage III \\
\hline & Metastatic & TNM Stage IV \\
\hline Bone tumours & \multicolumn{2}{|c|}{$\begin{array}{l}\text { Localized } \\
\text { Metastatic }\end{array}$} \\
\hline Retinoblastoma & Localized (intraocular) & IRSS Stage $0^{4342,41}$ \\
\hline
\end{tabular}




\begin{tabular}{|c|c|c|}
\hline & & IRSS Stage I \\
\hline & & IRSS Stage II \\
\hline & Regional (orbital and/or regional lymph nodes) & IRSS Stage III \\
\hline & Distant (extra-orbital) & IRSS Stage IV \\
\hline \multirow{4}{*}{ Hepatoblastoma } & \multirow{3}{*}{ Localized } & PRETEXT Stage I \\
\hline & & PRETEXT Stage II \\
\hline & & PRETEXT Stage III \\
\hline & Metastatic & PRETEXT Stage IV \\
\hline \multirow{3}{*}{ Testicular } & Localized & TNM Stage I \\
\hline & Regional & TNM Stage II \\
\hline & Metastatic & TNM Stage III \\
\hline \multirow{4}{*}{ Ovarian } & Localized & TNM/FIGO Stage I \\
\hline & \multirow{2}{*}{ Regional } & TNM/FIGO Stage II \\
\hline & & TNM/FIGO Stage III \\
\hline & Metastatic & TNM/FIGO Stage IV \\
\hline \multicolumn{3}{|c|}{ CENTRAL NERVOUS SYSTEM TUMOURS } \\
\hline \multirow{2}{*}{ Astrocytomas } & \multicolumn{2}{|c|}{ Localized } \\
\hline & \multicolumn{2}{|c|}{ Metastatic } \\
\hline \multirow{5}{*}{$\begin{array}{l}\text { Medulloblastoma and } \\
\text { other CNS embryonal } \\
\text { tumours }\end{array}$} & M0/Localized & M0 \\
\hline & \multirow{4}{*}{$\mathrm{M}+/$ Metastatic } & M1 \\
\hline & & M2 \\
\hline & & M3 \\
\hline & & M4 \\
\hline \multirow{5}{*}{ Ependymoma } & M0 & M0 \\
\hline & \multirow{4}{*}{$\mathrm{M}+$} & M1 \\
\hline & & M2 \\
\hline & & M3 \\
\hline & & M4 \\
\hline
\end{tabular}

Major updates are highlighted in bold

ALL - acute lymphoblastic leukemia; AML - acute myeloid leukemia; CML - chronic myeloid leukemia; CNS - central nervous system; FIGO - International Federation of Gynaecological

Oncologists; HL - Hodgkin lymphoma; INRGSS - International Neuroblastoma Risk Group Staging System; IRSS - International Retinoblastoma Staging System; MB - Medulloblastoma; NHL - nonHodgkin lymphoma; RCC - renal cell carcinoma 
Supplemental Table 1. Results of Delphi Round One Surveys

\begin{tabular}{|c|c|c|c|}
\hline Principle Statement & $\begin{array}{c}\text { No. } \\
\text { Responses }\end{array}$ & $\begin{array}{c}\text { Percent } \\
\text { Agreement* }\end{array}$ & $\begin{array}{l}\text { Median Score } \\
\quad(\mathrm{IQR})^{\%}\end{array}$ \\
\hline 1. Cancer registries should routinely collect data on non-stage prognosticators (NSP) for cases of pediatric cancer & 32 & 87.5 & $2(1-2)$ \\
\hline $\begin{array}{l}\text { 2. A primary reason for collecting NSPs in cancer registries, in addition to Toronto Stage, is to allow stratified } \\
\text { comparison of outcomes between groups or over time }\end{array}$ & 32 & 96.9 & $1(1-2)$ \\
\hline 3. Not all NSPs used clinically should be collected by cancer registries & 32 & 81.3 & $2(2-2)$ \\
\hline 4. The methods to measure the NSP must be reliable and reproducible in a clinical, not research, setting. & 32 & 93.8 & $1(1-2)$ \\
\hline 5. Wide availability of testing for the NSP must exist & 32 & 75.0 & $1(1-2)$ \\
\hline 6. Wide availability of testing for the NSP must exist across countries of different income settings & 32 & 62.5 & $2(2-3)$ \\
\hline 7. The definition of the NSP (including normal vs. abnormal) must be established ${ }^{* *}$ & 32 & 87.5 & $1(1-2)$ \\
\hline $\begin{array}{l}\text { 8. A NSP whose adverse prognostic impact can be overcome by modifying therapy should still be collected by } \\
\text { cancer registries.** }\end{array}$ & 32 & 84.4 & $1.5(1-2)$ \\
\hline 9. For cancers where multiple NSPs are highly correlated, cancer registries should only collect one of the correlated NSPs. & 32 & 34.4 & $3(2-4)$ \\
\hline $\begin{array}{l}\text { 10. For cancers with a large number of NSPs, a limited set should be prioritized for collection by population cancer } \\
\text { registries. }\end{array}$ & 32 & 81.3 & $2(1-2)$ \\
\hline \multicolumn{4}{|l|}{ 11. Prioritization of which NSPs to collect should be based on the following: } \\
\hline 11a. Prevalence & 32 & 65.6 & $2(2-3)$ \\
\hline 11b. Prognostic impact & 32 & 93.8 & $1(1-2)$ \\
\hline 11c. Feasibility & 32 & 90.6 & $1(1-2)$ \\
\hline 11d. Availability & 32 & 90.6 & $2(1-2)$ \\
\hline
\end{tabular}

- interquartile range; No. - number

*Agreement was defined as scores of 1 or 2 ;

$\% 1=$ strongly agree, $2=$ agree, $3=$ neither agree nor disagree, $4=$ disagree, $5=$ strongly disagree

**These statements were removed during the face-to-face meeting to avoid redundancy

Bolded principles indicate those achieving consensus by definitions outlined in text 